\title{
And so it all began: A personal tribute to the man behind the scientist
}

\author{
Marialuisa Aliotta ${ }^{1, \star}$ \\ ${ }^{1}$ SUPA, School of Physics and Astronomy, University of Edinburgh, EH9 3FD Edinburgh, United Kingdom
}

\begin{abstract}
At the time I began my scientific career as a PhD student under the supervision of Claudio Spitaleri, the Trojan Horse Method was still in its infancy. Like with any new-born idea, it took time and passion and effort to plant the early seeds that would eventually develop into a now well-established method in nuclear astrophysics research. Here, I offer my own recollection of those early years as a personal homage to Claudio's unique mix of human traits that shaped our professional relationship for many years since.
\end{abstract}

\section{Preamble}

If you work in the field of Nuclear Astrophysics and hear about a Trojan Horse Method (THM) experiment, you immediately identify it with the group in Catania, and more specifically with the group of Prof. Claudio Spitaleri. Yet, a little less than two decades ago, almost no-one in the field would have heard about the Trojan Horse Method. And those few who had, would probably have not concealed their skepticism about it. It was an indirect method based on a quasi-free breakup mechanism that under appropriate conditions could be used for nuclear astrophysics studies otherwise difficult to access with direct approaches [1].

On paper, the method was brilliant in its simplicity: much like Ulysses had managed to overcome the walls of Troy by hiding his men and himself within the belly of a huge wooden horse brought to the city as a gift $[2,3]$, so could a little particle overcome the repulsive Coulomb barrier of a targeted foe by being brought into it hidden inside a suitable Trojan horse nucleus. This way, the reaction of astrophysical interest could be studied unhindered by the Coulomb suppression and essentially devoid of any electron screening effect, a still-puzzling phenomenon that plagues direct measurements at extremely low energies.

It just seemed too good to be true! Surely, there must have been some hidden issues that were not immediately obvious at a first glance? And indeed some there were. Firstly, the method did not allow for a measurement of the absolute cross section of any nuclear reaction and as such relied on the existence of direct data, at least at high energies, for normalisation purposes. Secondly, it had to fulfil a number of strict validation tests. For example it was necessary to distinguish (and only select) the quasi-free mechanism events from those generated by any other process (e.g. sequential decay) leading to the same particles in the final state. Thirdly, it required making sure that the other particle (effectively the Trojan horse companion) did not take part in the interaction and left the scene

^e-mail:m.aliotta@ed.ac.uk 
of crime as a spectator. Of course this called for a non-trivial theoretical formalism and that too was rather complex and still in its infancy.

The method, and indeed its name, had already been proposed by Gerard Baur in 1986 [4] as a possible way to study reactions of astrophysical interest without the challenges posed by low-energy direct measurements. Yet, somehow, the suggestion had not been picked up until the late-mid 1990s. By that time, Claudio Spitaleri had already been working on break-up mechanisms for almost twenty years along with Marcello Lattuada, Francesco Riggi, Domenico (Mimmo) Vinciguerra, Djuro Miljanic, Mile Zadro, and others. By then, Claudio had realised that the idea proposed by Baur had a lot of potential and decided to pursue it at maximum speed. Luckily for me, this also coincided with the beginning of my $\mathrm{PhD}$ in 1995.

\section{Chance encounters}

I had graduated in physics in 1993 with a thesis on the use of radioactive ion beams for the study of the ${ }^{19} \mathrm{Ne}(\mathrm{p}, \gamma)^{20} \mathrm{Na}$ reaction in the context of nova explosions. Mine was the first undergraduate thesis in nuclear astrophysics at the University of Catania. Indeed, the field itself was probably very little known there at that time. In fact, I had found out about it almost accidentally as I attended a seminar given by a nuclear physicist from my home university, Prof Mimmo Vinciguerra, a few months before deciding on the topic of my thesis. In his seminar, Vinciguerra was reporting about new prospects to study nuclear reactions of interest to explosive astrophysical scenarios thanks to the possibility of creating and accelerating short-lived unstable nuclei for the first time. This opportunity was just emerging. At the Centre de Recherche du Cyclotron in Louvain-la-Neuve, Belgium, people had come up with the idea of coupling two existing cyclotrons to first produce and then re-accelerate radioactive nuclei to energies of astrophysical interest. This - Vinciguerra said in his seminar - would open up exciting new opportunities for research in Nuclear Astrophysics, a relatively new branch of science focussed on understanding the origin of the elements and the evolution of stars and galaxies. I got fascinated and quickly decided that this would become the topic of my thesis. Vinciguerra agreed to supervise me, jointly with Prof Aldo Zappalà from the Astronomical Observatory in Catania, and as part of my undergraduate thesis work I went to Belgium to take part in the ${ }^{19} \mathrm{Ne}(\mathrm{p}, \gamma)^{20} \mathrm{Na}$ experiment.

In the summer of 1993, a few months after my graduation, another chance encounter unfolded that would eventually prove to be crucial not only for my career, but also, as I will explain, for the dissemination of the THM beyond its initial restricted playground. At a summer school on Exotic Nuclei in Belgium, I happened to meet Prof Claus Rolfs, a world-leading figure in nuclear astrophysics and author of the book, Cauldrons in the Cosmos [5], by many regarded as the 'bible' in the field. I approached him during a coffee break and asked whether I might spend time at his institute in Germany. He replied that as long as I had funds of my own, I would be very welcome. So, I decided to apply for a scholarship from my university to spend a year abroad and moved to Bochum in 1994 at the Lehrstuhl für Ionenstrahlen of the Ruhr-Universität Bochum, Germany, led by Claus Rolfs. By the time I returned to Catania a year later I knew I wanted to do a $\mathrm{PhD}$ in Nuclear Astrophysics and I wanted it to be on an experimental nuclear physics project. I just did not know on what. The initial plan had been for me to continue working with Zappalà and Vinciguerra, so I started taking part in some experiments by the nuclear physics group at the Laboratori Nazionali del Sud (LNS) of the Istituto Nazionale di Fisica Nucleare (INFN) in Catania. That is when I met Claudio for the first time.

One day I was sitting on my own in the PhD students' office, feeling slightly unsure about what to do and which direction to take. Unexpectedly, Claudio came along and started asking me about my plans and stressing how important it was that I began working on a specific project as soon as possible. I guess the very fact that he showed interest in me, at a time where I was feeling somewhat under the 
weather, and the fact that he seemed to have a better idea about what I should do than I did, got me interested in the Trojan Horse Method and persuaded me to go for a change of project and supervisor.

It was soon after our initial chat that I started telling Claudio about my experience in Germany and how much I had enjoyed being in Rolfs' group. He showed great interest in finding out more about what I had done in Germany and it became clear that he too would have liked to meet the man. He did not know yet, but chance was around the corner once again, ready to offer another opportunity. In those days, Rolfs was spending a sabbatical in Naples as part of the $\mathrm{NaBoNa}$ collaboration with Prof Filippo Terrasi and his group. No sooner did I mention this to Claudio that he decided we should all go to Naples to visit him in person! Of course, by 'we' I mean just the three of us: Claudio, myself and Silvio Cherubini, Claudio's first PhD student who had just completed his doctorate. That's all who we were as far as the nuclear astrophysics group in Catania was concerned.

Claudio's quick decision to leave for Naples as soon as feasible summarises much of the attitude he has always had towards his work and was, as I would learn later, a typical trait of the enthusiasm and passion he poured into any new adventure he would embark on. So, without wasting time, I got in touch with Rolfs and asked whether it was ok for us to fly to Naples to meet him. Needless to say, he was delighted and quickly agreed to the plan with his usual, jovial cheerfulness. I do not remember much of that trip, except for a brief moment that still sticks indelible in my memory and that again epitomises much of Claudio's personality. We had just left the Physics Department in Naples after meeting with Rolfs and discussing with him about the THM. As we were walking towards our hired car, Claudio suddenly stopped in the middle of the path - tall eucalyptus trees all around us - looked at Silvio and me and, branding his finger mid air, with a tone required of solemn occasions, said: "Remember this day?! One day, maybe ten or twenty years from now, when we will have established a big group and everyone will know about us, you will think back at today and say "That's when it all began!"”.

\section{The early days of ASFIN}

Back at the lab in Catania, one of my first tasks was to write a research proposal that would form the basis of my $\mathrm{PhD}$ project. The idea was to use the THM to investigate the elastic scattering of ${ }^{12} \mathrm{C}+{ }^{4} \mathrm{He}$ as a validity test [6] towards the study of the ${ }^{12} \mathrm{C}(\alpha, \gamma){ }^{16} \mathrm{O}$ reaction, arguably one of the most important reactions in the field. Perhaps, you might think that tackling a simpler problem in nuclear astrophysics would have been wiser for someone approaching this field with an indirect method that was still very much in its infancy. But again, Claudio's personality says a lot about this choice. As he would often remind me for years: "Si t'ha mbriacari, mbriacati di vinu bonu!", a Sicilian phrase which roughly translates as "If you wish to get drunk, do so with quality wine!", an apt mantra to his philosophy of life. And so it was that we started to apply for funds under a new project name: ASFIN, simply standing for AStroFIsica Nucleare. That acronym still survives today as a highly successful research line within INFN.

Yet, if we wanted to turn the THM method from a mere idea into a well-established tool for nuclear astrophysics studies, we needed much theoretical support and a more sophisticated formalism. In those days, a German professor from the Ludwig-Maximilian Universität in Munich used to spend extended research visits at the Laboratori Nazionali del Sud di Catania. That professor was Hermann Wolter, who had recently collaborated with his post-doc Dr Stefan Typel precisely on matters closely related to the THM. Claudio discussed things with him and soon agreed to send me on a research visit to Munich. That again marked the beginning of many years of close collaboration which took the THM to a whole new ground.

As part of my $\mathrm{PhD}$, Claudio also suggested that I should spend a period of six months back in Bochum. In part, this decision was dictated by the desire to test some new monolithic $\Delta \mathrm{E}-\mathrm{E}$ silicon 

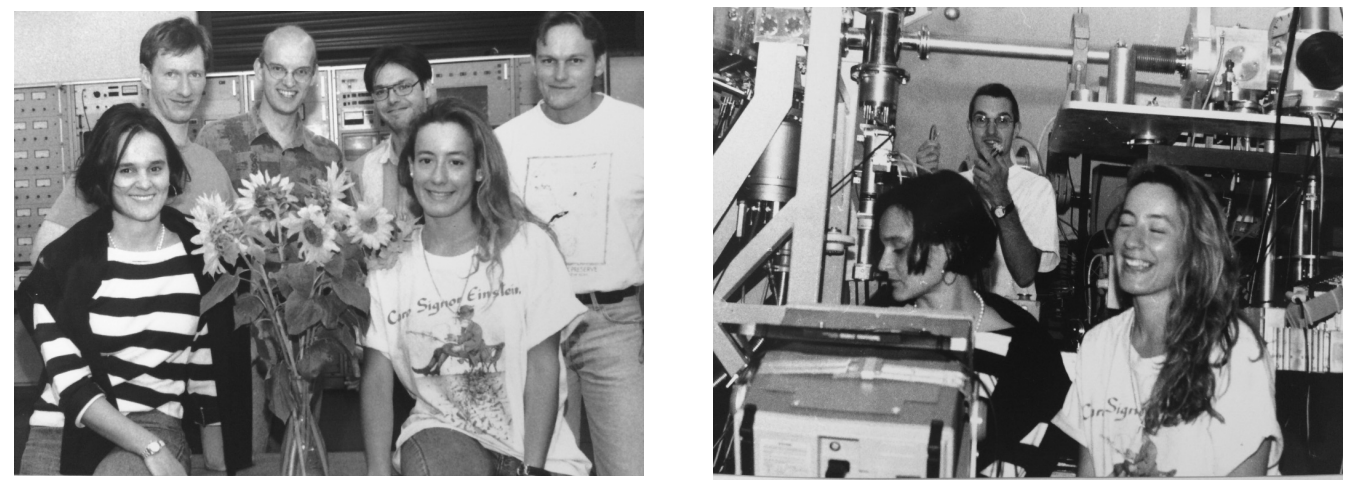

Figure 1: (Left panel) Two ladies at the DTL: Aurora Tumino (front right) and I (front left) with a bunch of flowers given to us by our German colleagues (behind us). (Right panel) Is someone sabotaging our experiment behind our backs? Aurora thinks this is funny!

detectors that were being developed in Catania as a collaboration between LNS and STMicroelectronics. But that of course, much like a Trojan horse, was just a pretext: more importantly Claudio was exploiting the opportunity as a way to further establishing and consolidating a closer collaboration with Rolfs. Soon after I arrived in Bochum for the second time, I was asked to give a group seminar about the Trojan Horse method and this quickly became a hot topic of discussion both within the group and outside it, with other close collaborators of Claus. A seed had been planted to disseminate the idea further.

My second time in Bochum was simply fantastic. Every member of the group, all males as it happened, were incredibly eager to offer their support. Probably this was further helped by the fact that now two girls were around at the Dynamitron Tandem Laboratorium (DTL) in Bochum (Figure 1): one was me, the other was Aurora Tumino (a young student at that time working with Marcello Lattuada in Catania) whom Claudio had decided to involve in our scientific adventures.

As for Claudio, he was always there with us in the front line. I still remember the day before our first experiment in Bochum! I hadn't slept in 36 hours trying to get everything ready for beam time. Before reinforcements arrived from Catania, I had been in charge of preparing every aspect of the experiment, from testing the detectors, assembling the electronics, and testing the data acquisition system, which proved to be the hardest part back in the days of a multi-parameter box that no-one had used before. I was exhausted and worried that something might go wrong. Just as we were about to receive beam on target, Claudio sat by my side at the acquisition desk, to support and encourage me: all will be fine. The experiment, or rather the test, proved somewhat inconclusive, but it was enough for us to have started putting another foot on the international context.

\section{The scientist, the mentor, the man}

It would be impossible here to recall the many trips and adventures we shared throughout the years that followed; the places we visited; the experiments we performed; the laughter and the companionship I experienced during the time of my $\mathrm{PhD}$. Those of us who were around in those days may still remember when I shamelessly mingled with the guests of a wedding banquet in the foyer of Schoenbrunn Palace in Vienna, at the margin of a conference Claudio had been invited to; or the time during the 1996 Nuclei in the Cosmos conference in Notre Dame when Silvio and I were desperately 

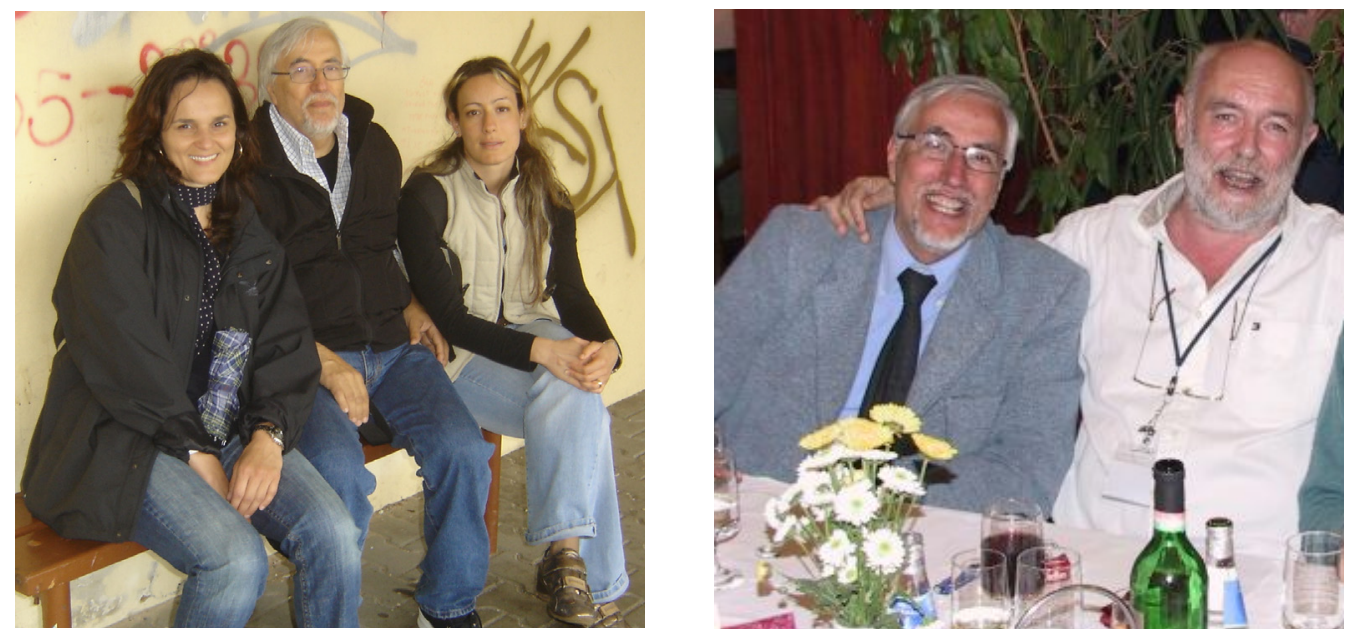

Figure 2: (Left panel) Claudio, Aurora and I at a bus stop somewhere in Europe. (Right panel) Claudio and Claus (right) enjoying wine at a conference dinner.

looking for a shoe shop only to end up calling for a taxi from the desk of a down-town bank; or still the night at a restaurant in Louvain-la-Neuve when the waiter brought a Dame blanche dessert to the table when in fact Silvio had called for an 'ambulance' for Claudio who was feeling unwell; or the time at the Steakhouse Argentinien in Bochum where I suggested to Claus and Claudio that we should start a summer school in Nuclear Astrophysics, now famously known within the community as the ' $\mathrm{St}$ Tecla' School.

We travelled extensively, always establishing new connections and planting the seeds for new collaborations and friendships that last to this day (Figure 2). Behind every trip and every new initiative was Claudio's unwavering enthusiasm, his desire to go always a step beyond and make his dream come true even in the face of personal tragedy.

Today, the ASFIN group, or Claudio's group (Figure 3), or the Trojan Horse Method, are one and the same. Even by modern standards and metrics, the THM has made for a truly successful story: over 300 papers published to date (with some 120 submitted in the last five years alone); more than 150 invited talks at international conferences; international collaborations with over 70 scientists from more than 30 different countries. The legacy is huge.

As a scientist, Claudio has had the ability to look ahead where no-one else had dared; to stick with his intuition that the method had potential; and to do all he could to make it widely recognised and established. This he has accomplished thanks to his ability to constantly enthuse new recruits and engage established scientists, not least several theoreticians who have further developed the method to adapt it to resonant reactions and, more recently, to reactions with radioactive nuclei [7]. Over the years, the Catania group has steadily increased in size and many students have taken their first steps under Claudio's protective wing towards now-established research careers.

As a mentor and supervisor, Claudio was always present to support and encourage; to challenge and reward. He constantly engaged me in decisions about the group's next moves; involved me in meetings with senior scientists; and generally made me feel I was his peer, not just his PhD student. Of course, this was not out of insecurity or indecision, but rather out of a deep rooted desire to share his vision for the future he had in mind. It wouldn't be fair to claim that working with Claudio has 


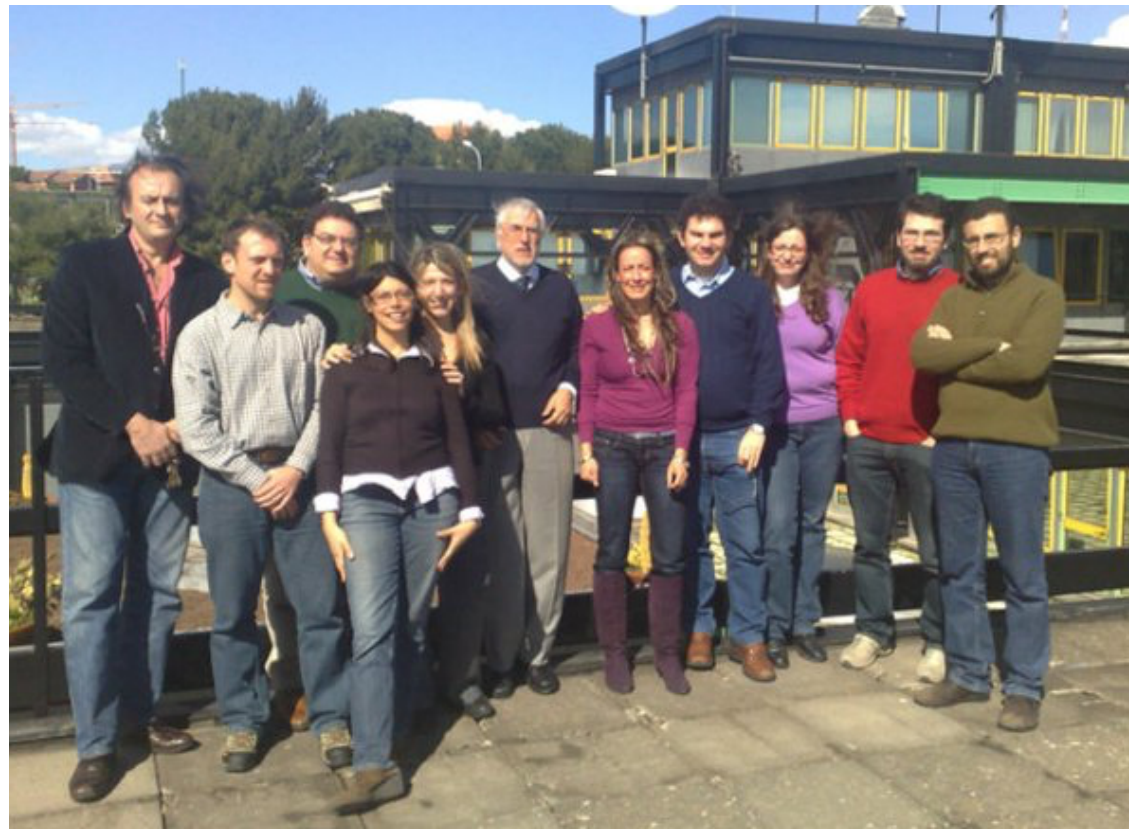

Figure 3: The ASFIN group in Catania (as of 2010. From left to right: Stefano Romano, Gabor Kiss, Silvio Cherubini, Marisa Gulino, Nellí Puglia, Claudio Spitaleri, Aurora Tumino, Gianluca Pizzone, Roberta Spartà, Marco La Cognata, Giuseppe Rapisarda (photo credit: G. Pizzone).

always been easy. We have certainly had discussions at times and occasionally strong disagreement, but there has always been a deep mutual respect and the deliberate intention to find new ways forward.

Yet for me, the most important trait of Claudio's personality has always been his humanity. And this is what I have cherished the most throughout the years. More than a supervisor, Claudio has been like a father figure. Someone I could go to when things, professionally and personally, had taken an unexpected turn, like when I left Germany to take up a permanent lectureship in the UK in 2001 or when my entire family moved away from Sicily just a few months afterwards. Throughout the many changes in my life and some moments of darkest despair, he has remained a constant presence and a reference point: someone I could get back to for advice or encouragement at every step along the way. For this, I am immensely grateful.

\section{Afterword}

As I sign off this contribution, I would like to take the opportunity to express my deepest gratitude to my many colleagues in Catania, who have been and continue to be some of my closest, dearest friends: Aurora Tumino and Stefano Romano, for teasing me in their truly unique way that makes me laugh with tears in my eyes every time we are together; Silvio Cherubini and Gianluca Pizzone (the 'before' and 'after' me), the former for constantly arguing with me about physics, the latter for taking much of the advice I had to offer as he followed in my own footsteps; and all the 'new' recruits, most of whom I never really worked with but who have always welcomed me back to the group making me feel one of them. To Marco La Cognata, Livio Lamia, Roberta Spartà, Giuseppe Rapisarda, Maria 
Letizia Sergi, Marisa Gulino, Sebastiana (Nellí) Puglia, Luca Guardo, and to all the new students in the group, my greatest wish for you is that you may enjoy plentiful and successful careers, paying tribute to the wonderful legacy that Claudio has left for us all.

Today, I am always pleased and proud to be able to fly back to Catania, my home at heart, and to see how much things have moved forward since the days of my $\mathrm{PhD}$. It is always a pleasure to see Claudio and notice how nothing has changed of his indomitable enthusiasm and passion for his work.

For me, the success of a scientist is measured not by the number of papers he or she has published, or by the astronomical personal h-index he or she might have achieved, but by the knowledge that he or she has left an imprint, a legacy, something for others to live on. This, Claudio, is what you have accomplished. If you ever look back, rejoice in the awareness that yours has been a career truly well spent.

\section{References}

[1] C. Spitaleri et al., Physics of Atomic Nuclei, 74 (2011) 1725.

[2] Homer, Odyssey, 8th century BC.

[3] Virgil, The Aeneid, 29-19 BC.

[4] G. Baur, Physics Letter B 178, 135 (1986).

[5] C.E. Rolfs and W.S. Rodney, Cauldrons in the Cosmos (The University of Chicago Press, 1988).

[6] C. Spitaleri, M. Aliotta, et al., European Physical Journal A7 (2000) 181.

[7] C. Spitaleri, et al., European Physical Journal A52 (2016) 77. 
